\title{
ALCOHOL AND DRUG INTOXICATIONS IN ADOLESCENTS ADMITTED TO PAEDIATRIC WARDS IN THE CZECH REPUBLIC: 5-YEAR RETROSPECTIVE STUDY 2006-2010
}

\author{
Pavel Kabíček ${ }^{1}$, Jiří Kobr², Lumír Šašek², Zita Obdržálkováa ${ }^{3}$, Ludmila Svitálková4, Věra Hůrková4, Jiří Zeman ${ }^{5}$ \\ 1 Department of Paediatrics, Thomayer Hospital and First Faculty of Medicine, Charles University, Prague, Czech Republic \\ ${ }^{2}$ Department of Paediatrics, Faculty of Medicine, Charles University, Pilsen, Czech Republic \\ ${ }^{3}$ Department of Paediatrics, Faculty Hospital Ostrava, Ostrava, Czech Republic \\ ${ }^{4}$ Department of Paediatrics, District Hospital of T. Bata, Zlín, Czech Republic \\ ${ }^{5}$ Department of Paediatrics, General Faculty Hospital and First Faculty of Medicine, Charles University, Prague, Czech Republic
}

\section{SUMMARY}

Objectives: The aim of the study was to establish frequency, severity and circumstances of alcohol and drug intoxications in adolescents admitted to inpatient wards in the Czech Republic.

Methods: Chief physician of each participating ward (or their designated deputy) searched the patient records for required information. The data was then statistically processed.

Results: Thirty inpatient paediatric wards participated in the study (27 district wards and 3 university hospital wards), amounting to more than a third of all paediatric wards in the country. The total number of intoxications reported was 2,176, the majority of which were alcohol-related $(84.5 \%)$, followed by cannabinoids and, to a lesser degree, amphetamines. The number of alcohol intoxications increased by $22 \%$ during the 5 -year observation period, whilst the frequency of illegal drugs intoxications remained the same. We also observed an increase in the percentage of alcohol intoxications in girls - from $42 \%$ to $45.5 \%$. The mean age at intoxication was low - 15.5 years. The Glasgow Coma Scale in individual episodes of intoxication increased during the study duration/follow up period. The proportion of alcohol intoxications originating in pubs, clubs or other public institutions was $25 \%$.

Conclusion: The number of alcohol intoxications has risen during the observation period. The age at which these intoxications occurred is very low. Of serious concern is the fact, that $25 \%$ of alcohol intoxications originated in places where alcohol is sold, despite the fact that majority of the adolescents were under the legal drinking age limit of 18 years.

Key words: alcohol intoxication, abuse of addictive substances, syndrome of risk behaviour in youth, adolescence, cannabinoids, CRAFFT

Address for correspondence: P. Kabiček, Department of Paediatrics, Thomayer Hospital, Videňská 800, 14059 Prague, Czech Republic. E-mail: p.kabicek@post.cz

https://doi.org/10.21101/cejph.a4644

\section{INTRODUCTION}

Alcohol and drug abuse is a serious part of risk behaviour in adolescents. Binge drinking especially endangers youth of European countries. Alcohol intoxication often plays part in accidents, traffic accidents, unprotected sex, sexual abuse during altered mental state, etc. The European School Survey Project on Alcohol and Other Drugs (ESPAD), which has been running in the Czech Republic since 1995 and is currently carried out in 35 countries, highlighted an increasing percentage of 16 years old pupils who consume excessive amounts of alcohol. In the Czech Republic in 1995 this amounted to $13.3 \%$, in 2011 to $19.9 \%$ (1). An increasing number of children and adolescents admitted to hospital wards for alcohol or other addictive substance intoxications was reported by all European studies, which pursued this trend in a given time period $(2-10)$.
The vast majority of epidemiological data concerning risk behaviour of adolescents is derived from questionnaires. Our study is clinically orientated, as it deals with sets of patients admitted to hospital wards. Future cooperation of paediatric wards in similarly composed study would enable data comparison in the respective time period.

\section{MATERIALS AND METHODS}

Thirty-two inpatient paediatric wards participated in the study, 2 wards failed to provide complete data for the entire 5 -year period, allowing for data from 30 institutions ( 3 university hospital wards and 27 district wards) to be processed, thus representing approximately one third of all paediatric inpatient wards of the Czech Republic. Paediatricians from the collaborating wards filled 
in a retrospective questionnaire containing information on age, sex, date of admission, duration of hospitalization; the number of hours in intensive care unit (ICU) and on artificial ventilation, if applicable, was noted separately. The Glasgow Coma Scale (GCS) and Paediatric Risk of Mortality (PRISM) score for those admitted to ICU was also noted. Furthermore, body temperature, blood alcohol level (\%), results of toxicologic assessment, if performed, concomitant diagnoses (ICD 10 - International Classification of Diseases) and detailed abuse-related circumstances such as the type of alcoholic beverage or drug, where it was taken (with whom or whether alone), were collected.

The data was statistically processed and evaluated using the $\mathrm{R}$ language platform*. Mathematical variables were expressed as mean, median and standard deviations. To compare incidence of injuries in males and females, Fisher's test was used, logistic regression was applied to determine the injury likelihood dependency on other variables.

\section{RESULTS}

Between 2006 and 2010, a total of 2,176 adolescents were hospitalized in 30 paediatric wards for addictive substance abuserelated acute conditions, out of which 1,838 were cases of alcohol intoxications, whilst other substances, predominantly illegal drugs, caused 338 cases. Number of patients admitted to hospitals increased gradually - in the course of 5 years from a total of 372 (in 2006) to 438 (in 2010), representing 18\% increase, no lethal intoxication was reported. Number of males was significantly higher $(1,207)$ than females $(969), p<0.001$. Average age in 2005 and 2010 was 15.1 years and 15.6 years, respectively.

\section{Alcohol}

The number of adolescents hospitalized for alcohol intoxications increased from 307 in 2006 to 375 in 2010 . The majority of this increase was observed during the 2006-2007 period, after that the numbers levelled off. There was an increase in the percentage of alcohol intoxications in girls - from $42 \%$ to $45.5 \%$.

GCS was evaluated in $91.3 \%$ of admissions. Normal GCS or mild consciousness impairment (GCS 13-15) was observed in 1,252 adolescents (68\%), moderate impairment (GCS 9-12) in $303(16.5 \%)$, and severe impairment (GCS 3-8) was observed in $281(15.5 \%)$ of adolescents. During the study duration, GCS increased with statistical (linear regression) significance, $\mathrm{p}<0.001$. Blood alcohol level at admission was between 0.4-4.7\%, 12 adolescents (10 males and 2 females) required artificial respiration support. Ventilation support was required for 3-24 hours. There were 3 patients with higher blood alcohol level presented upon admission with significantly lower body temperature, as low as 34 degrees Celsius. The type of alcohol ingested was determined in $74.7 \%$ of admission. $72 \%$ consumed spirits (with or without other alcoholic beverages), $15 \%$ reported only wine and $13 \%$ only beer. The circumstances of intoxication were noted in 1,414 cases $(65 \%)$. Most frequent was drinking on the street or in a park $(54.5 \%)$, in a restaurant or a party in a public place $(25.5 \%)$, in

*http://cran.r-project.org a house or an apartment (15.9\%), and lastly, at school, school dormitory or during school trip 3.4\% (Fig. 1). Adolescents were usually drinking in company of friends $(85.5 \%)$, only $14.5 \%$ of them were drinking alone.

\section{Other Drugs}

Various other addictive substances were found to be responsible for 338 cases of intoxications in adolescents (15.5\%), out of which 280 cases were selectively caused by illegal drugs. In all the remaining 58 cases, attempted suicide was quoted (50 times medicaments only, 3 times medicaments combined with smoking marijuana, 4 times medicaments combined with alcohol and once combination of all three aforementioned substances). Illegal drug intoxications were more frequent in males $(69 \%)$. Consciousness was impaired severely in $2.6 \%$ patients, moderately in $2.8 \%$ and mildly in $94.6 \% .39$ patients spent more than 2 days in ICU. Toxicology analysis revealed traces of tetrahydrocannabinol (THC) in 152 adolescents $(73.7 \%$ males) of average age of 15.4 years. One third of those also tested positive for alcohol and, in $8 \%$ of these, amphetamines were found as well.

Amphetamines were found in 82 patients $(3.8 \%)$ of the average age of 16.5 years, more frequently in females (64\%). $15 \%$ of amphetamine intoxications were accompanied by positive alcohol blood test. Upon admission to hospitals, GCS was 9-15, hospitalization took 1-4 days (in ICU maximum of 1 day). Half of the adolescents from this subset had records of previous experience with abuse of drugs in their past medical history, one of them had been previously diagnosed with drug abuse-associated psychosis.

15 adolescents tested positive for opiates ( 8 males and 7 females), aged 12-18 years. Opiates were often abused with other addictive substances ( 4 times benzodiazepines, 2 times THC and alcohol, 2 times alcohol only). 4 of these patients had an underlying psychiatric diagnosis (opiates addiction, schizophrenia or phobias).

Less frequent reasons for admission were abuse of datura ( 5 times), psilocybe (4 times), toluene (3 times), and LSD (2 times) (Fig. 2).

\section{Comorbidities and Related Factors}

Injuries accompanied alcohol intoxication in $8.7 \%$, mainly involving the craniofacial region (from small cutaneous lesions

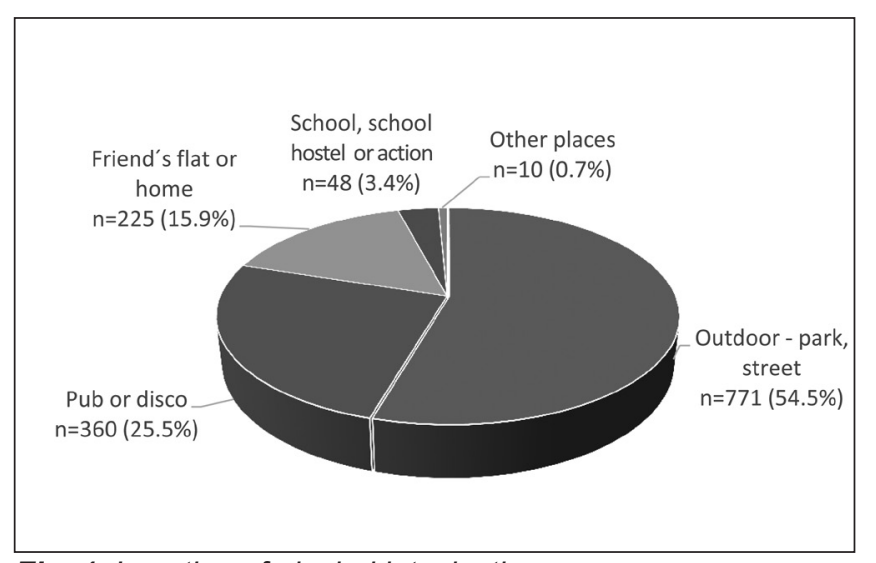

Fig. 1. Location of alcohol intoxication. 


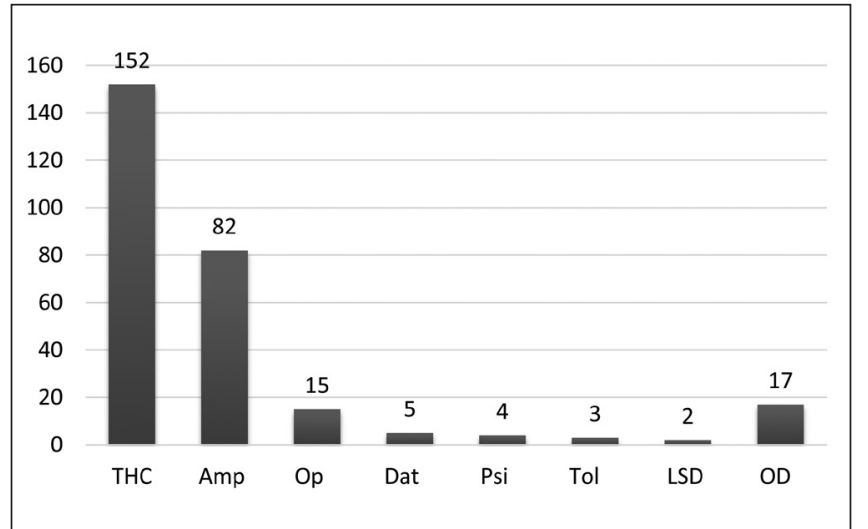

Fig. 2. Toxicological findings of illicit drugs $(N=280)$.

THC - tetrahydrocannabinol, Amp - amphetamines, Op - opiates, Dat - datura, Psi - psilocybe, Tol - toluene, LSD - lysergamid, O - other drugs

to lacerated wounds), cerebral commotion was diagnosed in 77 cases, orbital base fracture and cerebral oedema were both reported in one case, several patients suffered upper limp fractures, one case resulting in forearm amputation. Injuries were more frequently observed in males and in adolescents with lower GCS. Apprentices and pupils of reformatories and diagnostic institutions were often among the intoxicated patients.

\section{DISCUSSION}

\begin{abstract}
Alcohol
In European studies examining hospitalizations for adolescent intoxications, alcohol is the most frequent culprit, with only a slight preponderance of boys. The results of our study are consistent with these studies, which all showed increasing number of adolescents hospitalized for alcohol intoxication in time (2-10). Relevant comparison of acute intoxication incidence in adolescents to other countries is limited because the published studies are not only of somewhat regional importance, but they also concern variant age groups (Table 1). Certain comparison may be drawn between our results and a 2-year Dutch study, which analysed numbers of adolescents admitted to paediatric inpatient wards for alcohol intoxication between 2007-2008 $(3,10)$. This study processed data from $75 \%$ of paediatric inpatient wards, Dutch population of 11-18 years old adolescents being 1.4 million. Our study involves adolescents aged 10-19 years (population of approximately 1.05 million), data from $1 / 3$ of Czech paediatric inpatient wards were collected. In the Netherlands in 2008, a total of 337 adolescents were admitted to 56 paediatric inpatient wards for alcohol intoxication, in our country in the same period, a total of 367 patients were admitted to 30 wards. This data indicates a higher prevalence of alcohol intoxication in Czech adolescents and corresponds well with the findings of the European School Survey Project on Alcohol and Other Drugs. German nationwide statistics reported a total of 25,700 adolescents, aged 10-20 years, admitted to various hospital wards in 2008 (9). This appears to be a high number despite the inclusion of population larger than Czech and Dutch combined.

In the Dutch study, $15 \%$ of intoxications took place in restaurants or other alcohol serving premises (most commonly disco-
\end{abstract}

theques) (10), in Croatian study this was 19\% (2) and in our study $25 \%$. In our study, we noted 48 adolescents drinking directly on school premises. The Dutch (10), Croatian (2) and Slovakian (5) studies also looked into the geographical aspect of intoxication, although drinking in schools is mentioned neither in the Dutch nor in the Croatian study. It is highlighted in the Slovakian study, however, statistical data is not available. Drinking alcohol in schools, being a frequent reason for hospitalization, suggests a large-scale problem, especially because these hospitalizations represent almost certainly only the tip of the iceberg.

According to published studies, the average age of intoxicated teenagers is similar throughout Europe, i.e. 15.0-15.3 years in the Netherlands, 15.1 years in Slovakia, and 14.5 years in Germany. In the Czech study from 2005, the average age of alcoholintoxicated patients was 15.3 years (4). In our study, we observed an increased incidence of acute alcohol intoxication between 2006 and 2007. In Croatian study, the highest increase of alcohol consumption among youth was observed between 2003-2004. In German population of 15-19 years old males a twofold increase of alcohol consumption was noted in 2002-2008, this trend was correspondingly observed between 2004-2008 among females of the same age group.

The low age of alcohol intoxicated adolescents in our study demonstrates the necessity to approach this area of risk behaviour adequately as early as at 10 years of age.

Of 165 alcohol-intoxicated children and teenagers involved in the study carried out in Ostrava, Czech Republic, 4 patients required artificial ventilation support (blood alcohol level 3\% and higher) (4). In our study, ventilation support was provided for 12 patients, whose blood alcohol level ranged between 1.9-3.6\%o.

Alcohol misuse in apprentices accounts for many cases of intoxications. It is an established fact, that apprentices represent the highest risk group within the entire syndrome of risk behaviour in youth (1).

\section{Other Addictive Substances}

Except alcohol, the most commonly detected substance in acutely intoxicated adolescents admitted to hospital wards was THC, however, due to its long elimination half-life some of the positive results may be interpreted as residual reflection of past intake. THC was the sole toxicological finding in 91 cases (alcohol and other drugs were negative), in which acute collapse was the prevalent reason for admission. Overdose was most frequently observed after oral intake of THC, for example of cannabis boiled in milk (in multiple cases). The Spanish study, exploring cases of THC positive patients in ICUs over 2-year period, reported 72 intoxicated adolescents. The average age was 16.2 years, $60.6 \%$ were males, most frequent symptoms on admission were collapse and altered consciousness (40.3\%), agitation and restlessness (26.4\%). 16.7\% also tested positive for alcohol, 5.6\% tested positive for cocaine (11). The most frequent reason for hospitalization after smoking cannabis is collapse due to accentuated neurovegetative instability and postural or orthostatic hypotension (12), facilitated by THC effect on CB 1 receptors $(12,13)$.

The most popular drugs among problem users in the Czech Republic are psychostimulants. In our set of patients, 70 cases of such intoxications in adolescents were reported, surprisingly dominated by females (64\%). Long term abuse or addiction was 


\begin{tabular}{|c|c|c|c|c|c|c|c|c|c|}
\hline 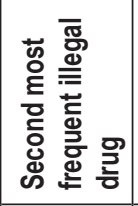 & $\frac{1}{2}$ & 罞 & 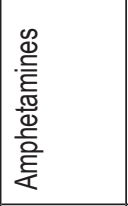 & $\frac{1}{z}$ & $\frac{1}{z}$ & $\frac{1}{z}$ & 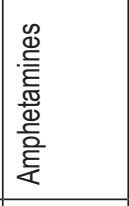 & 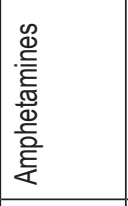 & $\frac{\mathbf{s}}{z}$ \\
\hline 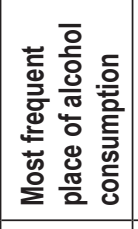 & 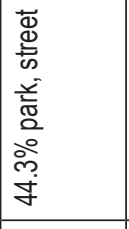 & 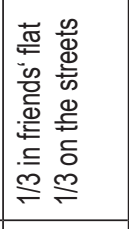 & 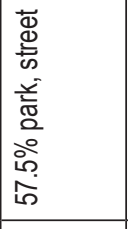 & 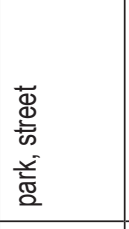 & $\frac{\sqrt{z}}{z}$ & 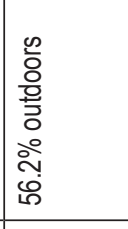 & $\stackrel{\mathbf{z}}{\mathbf{z}}$ & $\frac{1}{z}$ & $\underline{\Sigma}$ \\
\hline 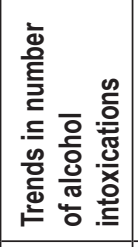 & 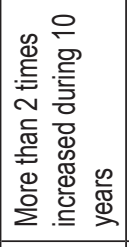 & 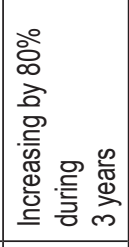 & 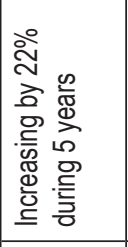 & 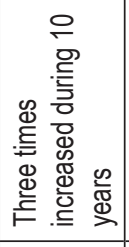 & $\frac{\pi}{z}$ & $\frac{1}{z}$ & $\underline{\mathbf{z}}$ & $\frac{\pi}{z}$ & 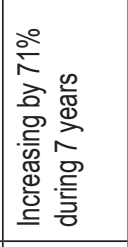 \\
\hline 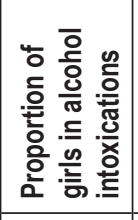 & 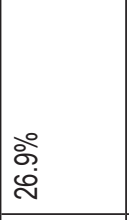 & 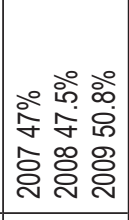 & 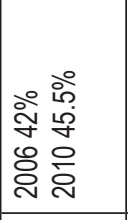 & 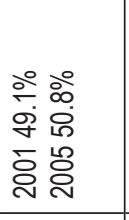 & $\begin{array}{l}\text { å o } \\
\text { ơ }\end{array}$ & 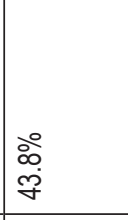 & $\begin{array}{l}\text { Oें } \\
\text { ò }\end{array}$ & 宫 & 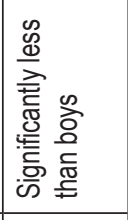 \\
\hline 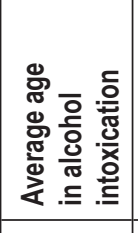 & 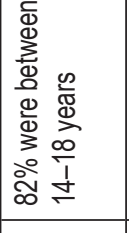 & 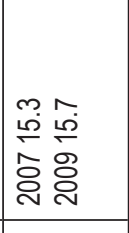 & $\begin{array}{l}\frac{0}{0} \\
\frac{\rho}{1} \\
\frac{1}{10} \\
\end{array}$ & $\underline{\underline{\rho}}$ & $\frac{\mathbf{s}}{z}$ & 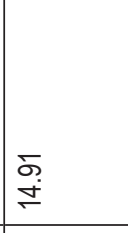 & 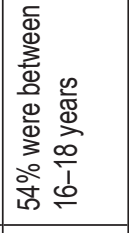 & 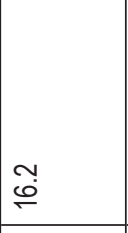 & 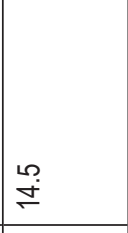 \\
\hline 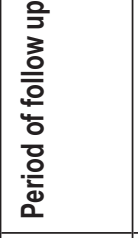 & 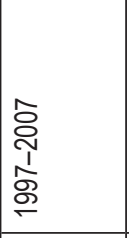 & 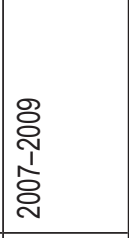 & 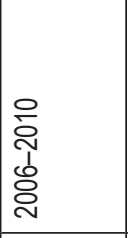 & $\begin{array}{l}\text { L̊ } \\
\text { ஸे } \\
0 \\
\circ \\
\end{array}$ & 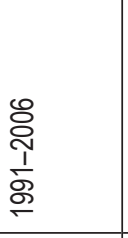 & 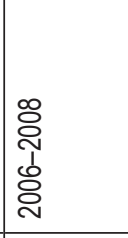 & 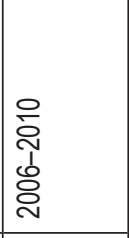 & ڤ్ & 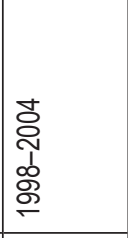 \\
\hline 8 & 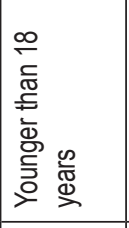 & 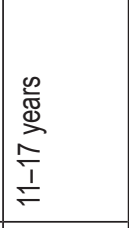 & 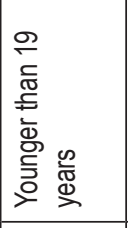 & 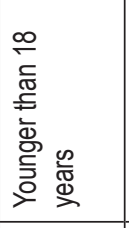 & 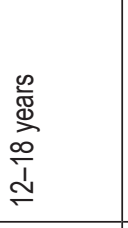 & 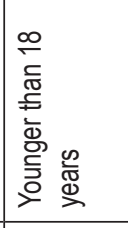 & 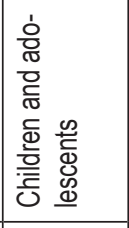 & 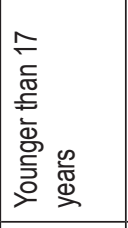 & 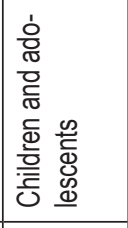 \\
\hline 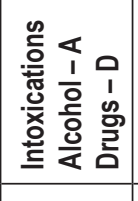 & $\varangle$ & $\begin{array}{l}0 \\
< \\
\end{array}$ & $\begin{array}{l}0 \\
< \\
\end{array}$ & $\begin{array}{l}0 \\
< \\
\end{array}$ & $\begin{array}{l}0 \\
<\end{array}$ & $\ll$ & $\begin{array}{l}a \\
< \\
\end{array}$ & $\begin{array}{l}0 \\
< \\
\end{array}$ & $\varangle$ \\
\hline 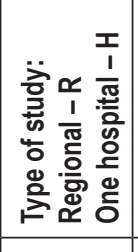 & 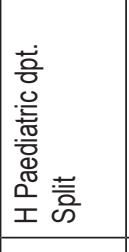 & 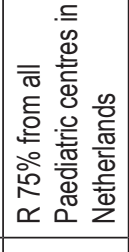 & 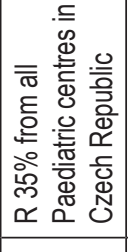 & 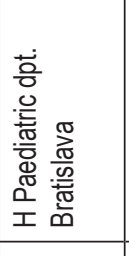 & 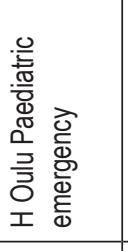 & 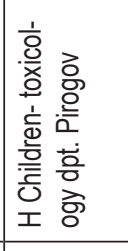 & 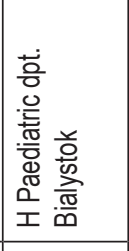 & 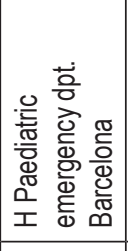 & 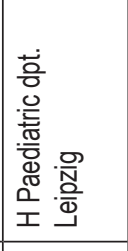 \\
\hline 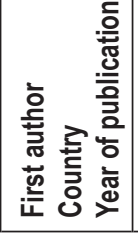 & 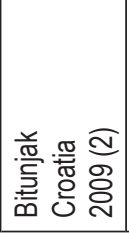 & 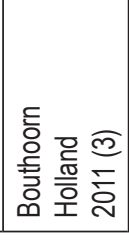 & 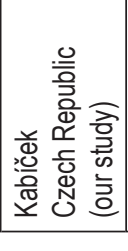 & 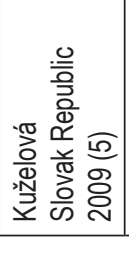 & 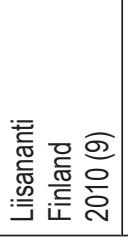 & 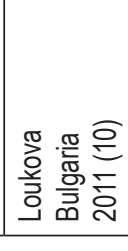 & 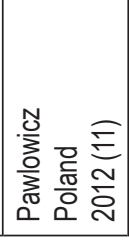 & 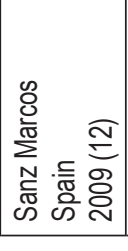 & 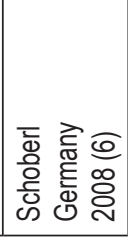 \\
\hline
\end{tabular}


ascertained in half of the cases. Opiates intoxication was diagnosed in 15 cases, in 7 of which opiate was the sole causative agent. Opiates intoxication is, however, often combined with benzodiazepines abuse for its augmented sedative and analgesic effect, increasing the risk of ventilation failure.

\section{CONCLUSION}

Numbers of adolescents requiring hospital admission for acute alcohol and/or other addictive substances is on the rise. Distillates consumption is the most common cause of severe alcohol intoxication. Recurring hospital admissions of intoxicated individuals (in our set of patients up to 5 times), suggest the necessity to improve parental, physicians' and teachers' knowledge in the area of substance abuse generally and also in individual cases. The CRAFFT questionnaire (14) may be a useful tool in paediatric practices. It determines the severity of an addictive substance misuse; its result directs the level of paediatrician's intervention or a referral to psychiatric follow up. Postgraduate courses on the use of the CRAFFT questionnaire, as well as practical training in suitable interventional techniques, is offered by well experienced addictologists and psychologists from the Division of Adolescent Medicine of Institute for Postgraduate Medical Education Prague (15), e-learning materials are also available (16).

Often, various other psychosocial issues are associated with acute intoxications of adolescents. Not surprisingly, drunk and intoxicated teenagers cause problematic situations in daily paediatric wards and ICUs operations - the risks lie not only in the aggressiveness and rapid behavioural changes of intoxicated patients but furthermore in disturbance of night operation routines. Acute situations management requires a complex medical team experience and expertise. Undoubtedly, intoxication-associated issues will have to be addressed in details by the Czech Paediatric Society. On global social scale, underage drinking and distribution of alcohol to underage individuals must be subjected to effective control mechanisms and preventive as well as repressive measures must be adopted in order to decrease addictive substance abuse in school environment.

\section{Acknowledgement}

Cooperating MDs and paediatric wards: Pavel Zeman, MD, Paediatric Department (PD) Hospital Brandýs nad Labem; Petr Havlovic, PD Municipal Hospital Č́slav; MUDr. Pavel Šochman, MD, PD Hospital Jablonec nad Nisou; Jan Petrželka, MD, Anežka Kudličková, MD, PD Hospital TGM Hodonín; Patricie Kotalíková, MD, PD Hospital Kadaň; Petr Lyer, MD, PD District Hospital Kladno; Marie Žaloudíková, MD, PD Krnov - Hospital Krnov; Jan Trubačík, MD, Iveta Jarmová, MD, PD Hospital Kyjov; Alena Štolcová, MD, PD Klaudián Hospital Mladá Boleslav; Jiří Biolek, MD, PD Hospital Most; Jindřich Hauk, MD, Mirka Slámová, MD, Lenka Slováčková, MD, PD Hospital Nové Město na Moravě; Dagmar Prejdová, MD, David Šupík, MD, PD Silesian Hospital Opava; Vladimír Němec, PD Hospital Pardubice; Josef Tenora, MD, PD Hospital Prostějov; Miloš Pavlík, MD, PD Masaryk Hospital Rakovník; Dalibor Karbula, MD, PD Sorbien Hospital Rumburk; Vladimír Cílek, MD, Petra Kinkorová, MD, PD Hospital Strakonice; Jan Malý, MD, PD Svitavy - Hospital, Svitavy; Jaroslav Procházka, MD, PD Hospital Teplice; Pavla Pokorná, MD, Kateřina Holá, MD, PD District Hospital Trutnov; Alena Holubová, MD, Jana Radvanová, MD, PD
Hospital Třebíč; Jan Petrželka, MD, PD Uherské Hradiště - Hospital, Uherské Hradiště; Luděk Ryba, MD, Ondřej Dvořák, MD, PD Ústí nad Orlicí - Hospital, Ústí nad Orlicí; Jan Boženský, MD, Jan Uhliř, MD, PD Vítkovice - Hospital, Vítkovice; Petr Bloudíček, MD, Jan Bourek, MD, PD Hospital Znojmo; Zdeňka Zasadilová, MD, PD Hospital Žatec. We would like to acknowledge Mgr. Jan Stuchlý for helping with statistics. This work was supported by Grant of the Ministry of Health of the Czech Republic No OZS/22/313/2011 and Grant of the Ministry of Health of the Czech Republic No RVO-VFN 64165/20

\section{Adherence to Ethical Standards}

Personal data was anonymised at the level of each ward. The study was performed according to the Helsinki Declaration, version of $2008 \mathrm{http}: / /$ www.wma.net/en/30publications/10policies/b3/17c.pdf and obtained institutional review board approval.

\section{Conflicts of Interest}

None declared

\section{REFERENCES}

1. ESPAD. European School Survey Project on Alcohol and other Drugs [Internet]. Stockholm: ESPAD; c2015 [cited 2015 Nov 24]. Available from: http://www.espad.org.

2. Bitunjac K, Saraga M. Alcohol intoxication in pediatric age: ten-year retrospective study. Croat Med J. 2009 Apr;50(2):151-6.

3. Bouthoorn SH, van Hoof JJ, van der Lely N. Adolescent alcohol intoxication in Dutch hospital centers of pediatrics: characteristics and gender differences. Eur J Pediatr. 2011 Aug;170(8):1023-30.

4. Hladík M, Olosová A, Boženský J, Gruszka T, Hájková K, Pavlíček J, et al. Alcohol intoxications of children and adolescents in Ostrava. Čes-slov Pediat. 2005;60(12):663-71. (In Czech.)

5. Kuzelová M, Harárová A, Ondriasová E, Wawruch M, Riedel R, Benedeková $\mathrm{M}$, et al. Alcohol intoxication requiring hospital admission in children and adolescents; retrospective analysis at the University Children's Hospital in the Slovak Republic. Clin Toxicol (Phila). 2009 Jul;47(6):556-61.

6. Liisanantti JH, Ala-Kokko TI, Dunder TS, Ebeling HE. Contributing factors in self-poisoning leading to hospital admission in adolescents in northern Finland. Subst Use Misuse. 2010 Jul;45(9):1340-50.

7. Pawłowicz U, Wasilewska A, Olański W, Stefanowicz M. Epidemiological study of acute poisoning in children: a 5-year retrospective study in the Paediatric University Hospital in Białystok, Poland. Emerg Med J. 2013 Sep;30(9):712-6.

8. Schöberl S, Nickel P, Schmutzer G, Siekmeyer W, Kiess W. Acute ethanol intoxication among children and adolescents. A retrospective analysis of 173 patients admitted to a university children hospital. Klin Padiatr. 2008 Jul-Aug;220(4):253-8. (In German.)

9. Stolle M, Sack PM, Spieles H, Thomasius R. Acute ethanol intoxication among children and adolescents in Hamburg, Germany. Bundesgesundheitsblatt Gesundheitsforschung Gesundheitsschutz. 2010 Sep;53(9):9106. (In German.)

10. van Hoof JJ, Van Der Lely N, Bouthoorn SH, Van Dalen WE, Pereira RR. Adolescent alcohol intoxication in the Dutch hospital departments of pediatrics: a 2-year comparison study. J Adolesc Health. 2011 Feb;48(2):212-4.

11. Velasco Arnaiz E, Trenchs Sainz de la Maza V, Curcoy Barcenilla AI, Velasco Rodríguez J, Matalí Costa JL, Luaces Cubells C. Who gives a positive cannabis in paediatric emergencies? An Pediatr (Barc). 2010 Jun;72(6):385-90.

12. Csémy L, Kabíček P, Hamanová J, Hellerová P. Effects of short-term and long-term usage of cannabinoids. Čes-slov Pediat. 2007;62(3):158-70. (In Czech.)

13. Gorelick DA, Heishman SJ, Preston KL, Nelson RA, Moolchan ET, Huestis MA. The cannabinoid CB1 receptor antagonist rimonabant attenuates the hypotensive effect of smoked marijuana in male smokers. Am Heart J. 2006 Mar;151(3):754.e1-754.e5. 
14. Harris SK, Csémy L, Sherritt L, Starostova O, Van Hook S, Johnson J, et al. Computer-facilitated substance use screening and brief advice for teens in primary care: an international trial. Pediatrics. 2012 Jun;129(6):107282

15. ipvz.cz [Internet]. Prague: Institute for Postgraduate Medical Education; c2015 [cited 2015 Nov 24]. Available from: http://www.ipvz.cz. (In Czech.)

16. Kabicek P. E- learning. Screening and brief intervention in anti- drug prevention in primary paediatricians surgeries [Internet]. Prague: Insti- tute for Postgraduate Medical Education; c2015 [cited 2015 Nov 24]. Available from https://www.ipvz.cz/o-ipvz/granty-a-projekty/odbornevzdelavani-lekarskych-a-nelekarskych-zdravotnickych-pracovniku-i/elearning-elektronicke-vzdelavani/e-kurz-screening. (In Czech.).

Received November 24, 2015 Accepted in revised form December 6, 2017 